\title{
Conjugate deviation as a presenting sign in a case of pontine tumour
}

\author{
G. G. SOOD, B. K. SOFAT, R. D. GHANDEL, AND M. SOOD \\ H.P. Medical College, Simla, India
}

Conjugate deviation of the eyes occurs mainly in cortical lesions and is infrequent in pontine lesions (Kestenbaum, I96I). It may be seen in advanced cases of pontine tumour with other well-marked localizing signs, but is rarely reported as the first sign. An interesting case, in which conjugate deviation of the eyes to the left was the first sign which brought the patient to our clinic, is reported below.

\section{Case report}

A 26-year-old male Hindu attended the Eye Out-Patient Department of Snowdon Hospital, Simla, on February I I, 197 I, with deviation of both eyes towards the left. He had been unable to look straight ahead or to the right for the previous 6 days.

\section{Examination}

The pulse and respiration were normal. Both eyes were turned permanently to the left, but on near fixation the power of convergence was found to be intact. No other neurological defect was found. The eyebrows, eyelids, and anterior segments were normal. Fundus examination revealed slight blurring of the right disc margin, giving the impression of very early papilloedema.

\section{Progress}

Admission to hospital for further investigations was advised but was refused.

The patient attended again on February 18, 1971, when the conjugate deviation to the left had become more marked, and there was right facial palsy of the infranuclear type. His condition grew worse and he agreed to come into hospital on February 22. He now complained of giddiness, nausea, occasional vomiting, and inability to walk unassisted.

\section{Examination}

Both eyes were turned to the left (Fig. I, overleaf), with facial palsy of the lower motor neurone type (Fig. 2, overleaf) and blunting of pharyngeal sensation on the right side, suggestive of right facial and glossopharyngeal involvement. There was a left extensor plantar reflex. The fundus showed increased papilloedema in the right eye with moderate blurring of disc margins in the left.

\section{Laboratory investigations}

Hb 14 g. per cent.; total leucocyte count 7,500/c.mm. (polymorphs 75 per cent; lymphocytes 20 per cent.; mononucleocytes I per cent.; eosinophils 4 per cent.); erythrocyte sedimentation rate $6 \mathrm{~mm} . /$ ist hr (Westergren).

Urine and stool examination showed no abnormality.

$X$ ray examination of the chest was normal. $X$ rays of the skull showed destruction of the clinoid processes. 




FIG. I Conjugate deviation to the left with both eyes open

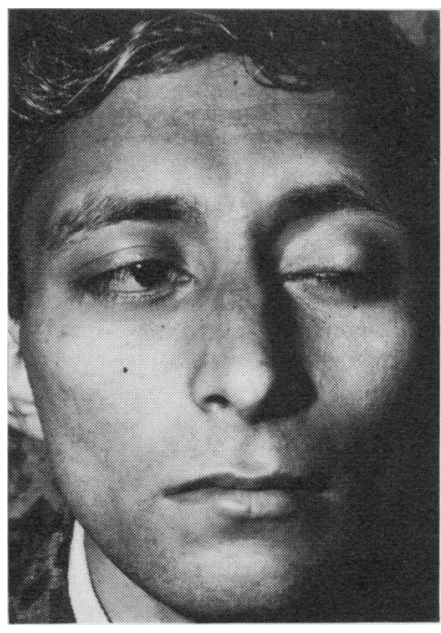

FI G. 2 Right facial palsy is evident as the patient attempts to close the lids

\section{Diagnosis}

A provisional diagnosis of glioma of the pontine region was made and the patient was referred to a neurosurgeon at Chandigarh.

\section{Neurological investigations}

Air and myodil ventriculograms revealed moderate dilatation of the lateral ventricles. The aqueduct of Sylvius and fourth ventricle were displaced posteriorly.

\section{Treatment}

The diagnosis of glioma of the brain-stem in the region of the pons was thus confirmed and the patient was given radiation therapy.

\section{Discussion}

The conjugate movements of the eyes are controlled by a cortical centre believed to be situated in the posterior part of the middle frontal gyrus (Wolff, r96r; Best and Taylor, I96I) and pontine centre. The latter is believed to be situated in the vestibular nucleus complex (Spiegel, I933), in or near the sixth nerve nucleus (Schneider, Kahn, and Crosby, I95I), with the sixth nerve nucleus, or along the lateral border of the medial longitudinal fasciculus (Haymaker, i 956).

Conjugate paralysis is frequent in lesions of the cortical centre. In early cases, if there is irritation of the centre, the eyes deviate to the opposite side, but later, when paralysis ensues, the eyes deviate to the same side. Conjugate deviation due to a cortical central lesion does not have long duration (Kestenbaum, I96I). In cases of pontine lesions, conjugate deviation is rare (Kestenbaum, I96I); this is because so many nuclei are compactly placed in a small space that it will be rare for any lesion to involve the centre of conjugate deviation alone, and by the time this centre is involved various other nerve nuclei will already have been affected.

In our case the initial lesion must have been of pin-point size, and must have started precisely at the pontine centre. The fact that the right facial nerve and possibly the right abducent nerve were spared for about 13 days, suggests that the pontine centre of 
conjugate deviation is distinct and lies some distance above the sixth nerve nucleus. The fibres from this centre, as Savas (1954) pointed out, descend to the ipsilateral sixth nerve nucleus and medial longitudinal fasciculus, and ascend to both the third nerve nuclei. Downward extension of the lesion, as in the present case, will involve the sixth, seventh, and glossopharyngeal nerves, and will spare convergence. Reese and Yaskin (194I) also reported preservation of convergence with paralysis of lateral movements in a case of intermedullary tumour.

\section{Summary}

A case of pontine tumour with conjugate paralysis as the presenting sign is reported.

It is postulated that the centre of conjugate movements in the pons is a distinct entity situated above the sixth nerve nucleus. A lesion of the pontine centre progressing downwards is likely to involve the nuclei of the sixth, seventh, and ninth nerves and to spare convergence.

Our thanks are due to Dr. B. P. Sinha, Principal, H. P. Medical College, Simla, and to Dr. D. S. Chauhan, Medical Superintendent, Snowdon Hospital, Simla, for their constant help and encouragement.

\section{References}

Baker, A. B. (1962) “Clinical Neurology”, 2nd ed., p. 483. Hoeber, New York

Best, с. H., and TAYlor, N. B. (196r) "The Physiological Basis of Medical Practice", 7th ed., p. 1418. Williams and Wilkins, Baltimore

HAYMAKER, W. (1956) “Bing's Local Diagnosis in Neurological Diseases", trans., rev., and enlarged

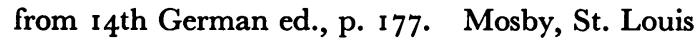

Kestenbaum, A. (1961) “Clinical Methods of Neuro-Ophthalmologic Examination", p. 322.

Grune and Stratton, New York

REESE, W. S., and YASKIN, J. C. (1941) Amer. F. Ophthal., 24, 554

SAVAS, A. (1954) Acta anat. (Basel), 21, 209

SCHNEIDER, R. C., KAHN, E. A., and Grosby, E. C. (195I) Neurology (Minneap.), r, 386

SPIEGEL, E. A. (1933) Arch. Neurol. (Chicago), 29, 1085

wolfF, E. (I96r) "Anatomy of the Eye and Orbit", 5th ed., revised R. J. Last, p. 357. Lewis,

London 